\title{
BLICKDIAGNOSE-QUIZ
}

Stellen Sie uns

Ihren Fall vor.

Bei Veröffentlichung erhalten Sie 100 Euro!

cornelius.heyer@ springer.com

\section{Warum ist die Mandel so groß und belegt?}

_ Ein 78-jähriger ehemaliger Landwirt stellte sich wegen einer schmerzlosen Veränderung seiner rechten Mandel vor. Außerdem hatte er einen Knoten im rechten Kieferwinkel bemerkt. Er berichtete, dass er bereits eine antibiotische Behandlung versucht hatte, was aber zu keiner Besserung geführt habe. Von einer B-Symptomatik konnte er nichts berichten. Risikofaktoren wie Nikotinabusus oder übermäßiger Alkoholkonsum bestünden nicht. Wegen eines Vorhofflimmerns nehme er Marcumar ein. Sonstige Erkrankungen lägen nicht vor.

Bei der Untersuchung fiel eine schmierig belegte, livide und vergrößerte rechte Gaumentonsille auf. Ansonsten war der Waldeyersche Rachenring unauffällig. An der rechten Halsseite ließ sich ein nicht dolenter, gut verschieblicher, mäßig derber Knoten von etwa $2 \mathrm{~cm}$ Größe tasten, der sich sonografisch weitgehend homogen echoarm mit scharfer Abgrenzung darstellte.
Wie lautet Ihre Diagnose?
A) Angina Plaut-Vincent
B) Epstein-Barr-Virus -Tonsillitis
C) Lymphom der Tonsille
D) Lues II
E) Tonsillenkarzinom

Auflösung auf Seite 82.

$\rightarrow$ Prof. Dr. Peter R. Issing

Klinik für Hals-Nasen-Ohrenheilkunde, Kopf- Hals- und plastische Gesichtschirurgie, Klinikum Bad Hersfeld, Seilerweg 29, D-36251 Bad Hersfeld

$\rightarrow$ Koautor: Dr. Heinz-H. Köhler, Marburg 